\title{
STUdent ANd FACUlTy EXPERIENCE WITH BLENDED LEARNing In A FiRST-YEAR CHEMISTRY FOR ENGINEERS COURSE
}

\author{
Eline Boghaert ${ }^{1}$, Jason Grove ${ }^{1}$, Marios Ioannidis ${ }^{1}$, Felicia Pantazi $^{2}$, and Mary Power ${ }^{3}$ \\ University of Waterloo, ' Department of Chemical Engineering, ${ }^{2}$ Centre for Extended Learning $\&{ }^{3}$ Centre for Teaching \\ Excellence \\ Eline.Boghaert@uwaterloo.ca
}

\begin{abstract}
CHE 102, Chemistry for Engineers, is an introductory chemistry course taken by most engineering students at the University of Waterloo during their first term of study. In an effort to create time for more valuable instructor-student interaction and to allow students to explore course content at their own pace, some lecture sections piloted a blended learning model for approximately half the Fall 2016 term. Data from surveys administered throughout the term were combined with course grade data in an effort to compare and contrast student experience, satisfaction and performance between a blended learning and traditional lecture model of instruction. While the results from the Fall 2016 study are inconclusive due to challenges with survey administration and implementing the blended learning model, lessons were learned with respect to the readiness of the students for self-directed learning and the integration of the online and in-class components. We plan on continuing this study during the Fall 2017 term.
\end{abstract}

Keywords: blended learning, online course development, comparing traditional and blended learning models

\section{INTRODUCTION}

CHE 102, Chemistry for Engineers, is an introductory chemistry course taken by most engineering students at the University of Waterloo during their first term of study. Prior to 2016, the course had always been offered in a traditional lecture format. During the Fall 2016 term, some lecture sections piloted a blended learning model for approximately half the course. The motivation for developing a blended approach was i) to create time for more valuable instructor-student interactions in the classroom, allowing the instructor to lead tutorials featuring either problem-solving workshops or experiential education activities as part of the IDEAS Clinic initiative (https://uwaterloo.ca/engineering-ideasclinic/), and, ii) to allow students to explore content at their own pace, thereby accommodating the diversity of students' high-school chemistry preparation.

As an introductory-level foundational course, $\mathrm{ChE}$ 102 has a diverse student population with respect to background knowledge, readiness for university and interest in the subject matter. Owston and colleagues determined that high-achieving students have a preference for, and fare better in, blended learning courses than their lower-achieving counterparts [1]. While in principle all students accepted into the engineering program at the University of Waterloo fall into the high-achieving category the realities of the diversities mentioned above result in a number of students falling behind. Blended learning models informed by evidence-based practice have enormous potential to address this challenge [2].

A recent meta-analysis of the effectiveness of blended learning provides evidence of its significant advantages over traditional classroom instruction, especially for Science, Technology, Engineering and Math (STEM) subjects [3]. The authors recommend that future research address questions related to instructional design, particularly the "blend" of classroom and online instruction which produces both deep and meaningful learning and more satisfying educational experiences [3].

Here we will provide some comments on instructor experience and preliminary results that compare and contrast student experience, satisfaction and performance between a blended learning and traditional lecture model of instruction.

\section{DEVELOPMENT OF THE ONLINE CONTENT}

The course consists of six modules, each of approximately two weeks. In collaboration with the Centre for Extended Learning at the University of Waterloo and using funding provided by the Ontario Ministry of Training, Colleges and Universities' Shared Online Course Fund, online content was developed to replace the lecture component of three modules. The modules were developed based on the principles of instructional design and special considerations were given to student-content 
interaction. The modules were developed and hosted in the newly released online courseware environment, Möbius. This platform allowed us to incorporate various types of media such as narrated slides, animations, simulations, videos. Adaptive learning was employed through concept checkpoints questions which allowed us to customize the feedback based on students' knowledge. These modules are openly available for use under a creative commons licence and can be found at http://open.engineering.uwaterloo.ca/.

\section{STUDY DESIGN}

The online content was deployed for the first time in Fall 2016. Total course enrolment was approximately 1400 students in twelve sections. The course comprises six modules, each of approximately two weeks duration. Ten sections were offered in a traditional format, consisting of three hours of lectures and two hours of teaching assistant-led tutorials each week. Two sections were taught in a blended format for the second, third and fifth modules (approximately half the course). In this format access to the online modules replaced lecture content, and the instructor led problem-solving and experiential activities. Class time was reduced for these students to maintain a consistent work load for the students across all sections. One instructor offered both the blended and traditional versions of the course to different cohorts enrolled in the same program. Short surveys were distributed electronically to all students at the start of term and at the end of each module. Questions on these surveys were phrased to address the following research questions:

1) Does the changed course format affect student reaction and experience?

2) Does the delivery method affect student confidence and self-efficacy?

3) Does the delivery method affect perceived effectiveness of content delivery?

4) Does the changed course format alter the perceived relevance and perceived value of ChE102?

Additionally, survey results were combined with course grade data to assess whether the changed course format affects student learning.

\section{RESULTS AND DISCUSSION}

\subsection{Instructor Experience}

The implementation of a blended learning model for half the course and a traditional model for half the course, as well as the collection of data for the purposes of this study, was much more challenging than the instructors had anticipated. Considerable challenges were caused by the need to flip back-and-forth between blended and traditional modes. First, this caused some confusion among the students in terms of anticipating when lectures would be held and so on. Secondly, the course was scheduled into a traditional lecture classroom in 1.5 hour periods; this room was not well-suited to the hands-on instruction and instructor-led problem-solving tutorials envisioned by the blended design. It was nearly impossible to reach some of the students in the center of the room and provide them with assistance. This also reduced the classroom time from the 2 hour periods intended for the blended learning component, making some sessions somewhat rushed and, at times, chaotic - in particular during the instructor-led hands-on experiential activities, which were intended to be a major benefit of the blended design.. While we had discussed some of these concerns prior to the course being mounted, we underestimated the associated challenges; in addition, we were obliged to offer the course by the terms of our funding.

Despite the challenges discussed above, the second course module, States of Matter, was delivered using a blended learning model and went fairly smoothly. Students were engaged during the instructor-led tutorial. Additionally, leading the tutorial gave the instructor the opportunity to interact with individual students and informally assess their understanding of the content and ability to solve problems.

The third module, Phase Equilibrium, was met with significant resistance. The majority of students have not been exposed to this content in high school and find it to be particularly challenging, regardless of the mode of delivery (this is supported both by the opinion of experienced instructors of this course and in the student surveys). This unit was scheduled to begin the week before midterm week and end the week after midterm week. As a result, the majority of students in the blended delivery sections neglected to begin the online content until after midterm week. Due to the nature of the material in this module, as well as its unfamiliarity from high school, the length of study time required is substantially higher than in the other course modules. Students expressed to the instructors that they found the content overwhelming. As a result of these students concerns, as well as an evident lack of preparation for the in-class sessions, the instructors felt it necessary to review content that the students were meant to have received online; this reduced the time available for the instructor-led tutorial activities. While giving in to students and re-teaching this content in class may have reinforced the notion that it's okay to neglect the independent learning assigned, the instructors felt that not doing so would have been detrimental to the learning experience for these students. 
A significant challenge for the research project was the lack of survey completion. Students were given a homework assignment grade based on survey completion. They were not required to provide research consent or to answer any particular survey questions, but were required to access the survey to receive this grade. Only $10 \%$ of students enroled in the course completed all seven surveys. Unfortunately, this was compounded by issues related to email delivery resulting from a major change to the student email system.

\subsection{Student Satisfaction}

Throughout the term the instructors noticed resistance towards the blended learning model, this was emphasized on the course critiques with many students leaving comments such as "stop using online modules." That being said some students did see the potential benefit of the blended model and the use of online modules. One student commented:

"In the end the electrochemistry unit was able to

change my mind about the course, I learned a lot with the simulations and since I'm usually slow this allowed me to learn at my own pace."

Overall, $74 \%$ of students preferred the traditional model, $12 \%$ preferred the blended model and $14 \%$ indicated no preference. Note that only $29 \%$ of the students enrolled in the blended sections participated in the survey and provided consent.

The implementation of a blended format also resulted in a lower overall appraisal of the quality of teaching based on course critique data. Teaching the course in a traditional format, the instructors have consistently received $90-95 \%$ in the past on a question regarding the overall quality of the course. In Fall 2016, when implementing the blended learning model, these same instructors received a $76 \%$ and $74 \%$ on this question.

\subsection{Perceived Effectiveness of Content Delivery}

Based on survey question "the concepts in this unit were clearly presented," students felt that for the most part concepts were more clearly presented in a traditional format, as shown in Figure 1. Sections 6 and 9 received the blended learning format for Units 2, 3 and 5 (triangle markers). Section 8 received the blended learning format for Unit 2 (triangle marker). All other sections received the traditional learning format (diamond markers). Of particular interest are sections 5 and 6 which were taught by the same instructor. Comparing these two groups the students felt that concepts were more clearly presented in a traditional format.

Student dissatisfaction with the Phase Equilibrium online module is apparent from these data. The majority of students in the blended sections disagreed with the statement that the concepts in module 3 were clearly presented. For the electrochemistry module, students in the blended section felt the concepts were more clearly presented than those in many of the traditional sections.

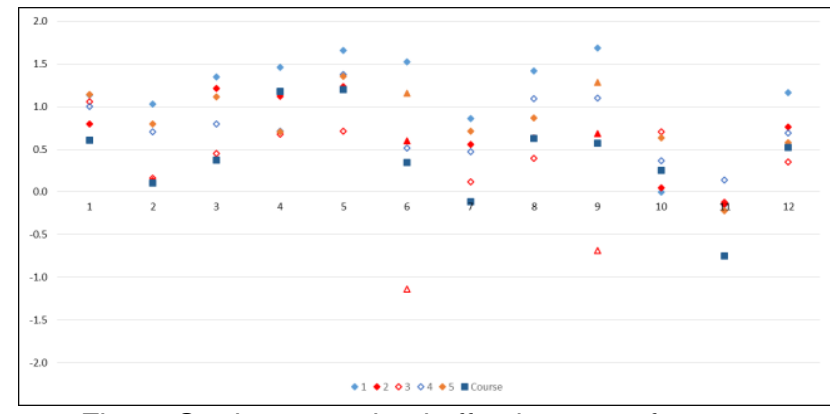

Fig. 1. Student perceived effectiveness of content delivery, based on average responses to the survey question "the material in this unit (course) was clearly presented" on a scale of strongly agree (2) to strongly disagree (-2). Blended and traditional modules are triangles and diamonds, respectively.

\subsection{Student Performance}

While many students seemed dissatisfied with the blended mode of delivery and felt that the concepts were not clearly presented, final exam grades show no significant differences between the two modes of delivery.

\section{CONCLUSION}

During the Fall 2016 pilot the instructors faced many challenges implementing the blended learning model as well as collecting data for the purposes of this study. Some of these were logistical in nature; for future offerings of the blended course, it is important that course meetings can be scheduled for the correct lengths of time and in appropriate locations. There were also significant pedagogical challenges. Many students did not follow the proposed schedule and resisted engaging with the second online module. In part due to the challenging nature of the content and due to the timing of this module around midterm exam week. As a result the instructors were forced to adapt and review some of the content in class. Moving forward, some revision to the online content is required. Additionally some mechanism to motivate students to engage with the online content at the correct time and demonstrate understanding of those concepts is required.

For Fall 2017 we intend to continue this study, this time with several sections of the course receiving the blended learning format for the entire course. We hope that presenting the entire course in one format will allow us to more readily communicate expectations to the 
students at the beginning of the term and will help with student "buy in". Part of the redesign will also include better use of the online materials by encouraging engagement, via tracking, with the concept check questions and more purposeful design of the in-class instructor-led sessions. We have also changed the order in which we present some of the content so that students can become more comfortable with the online delivery of content before they begin, what for many is the most challenging unit, Phase Equilibrium; this will also resolve the conflict of that module with the study break and midterm examination week.

We have learned a number of lessons that may be of value to instructors considering a blended course model. First, undertaking a course redesign of this nature requires very considerable time and effort; here, this effort was evident both in the design of the online material as well as the changes to the in-class component of the course. Furthermore, the redesign turns out to be a marathon rather than a sprint and we envisage that review and revisions beyond regular course maintenance will continue for the next several offerings of the course. Second, the blended learning paradigm requires the students to exhibit a different attitude and behavior towards the course. With hindsight, it was unreasonable to expect that students could readily "switch modes" between traditional and blended formats. In addition, it is important to ensure that students clearly understand the course design and philosophy; it was apparent from comments in course critiques and elsewhere that some students expected "to be taught" in a traditional classroom setting, rather than regarding the course as an environment for them to learn. It is also important to establish clear expectations around both what the students should be doing and when they should be doing it. Third, the collection of data about the course by survey has proved to be both challenging and valuable: challenging in terms of dealing with the ambiguities and surprises thrown up by survey data, but valuable in terms of facilitating course improvement via evidence-based insights. Finally, it is important to explicitly communicate with the students around the course design and expectations of both learner and instructor. We continue to believe that the blended learning model will eventually lead to better outcomes in this course and intend to continue to pursue our evidencebased approach towards course improvement.

\section{Acknowledgements}

Online content used in the blended offering of this course was developed with the support of the Centre for Extended Learning at the University of Waterloo and funding provided by the Ministry of Training, Colleges and Universities (MTCU).

This study was reviewed and received ethics clearance through a University of Waterloo Research Ethics Committee.

\section{References}

[1] Ron Owston, Dennis York, and Susan Murtha, "Student perceptions and achievement in a university blended learning strategic initiative," The Internet and Higher Education, vol. 18, pp. 38 - 46, 2013. Available as of April 12, 2017 from http://doi.org/10.1016/j.iheduc.2012.12.003.

[2] D. Randy Garrison and Normal D. Vaughan, Blended Learning in Higher Education: Framework, Principles and Guidelines. San Francisco, CA: Jossey-Bass, 2007, 272 pp. \{978-0-7879-8770-1\}

[3] Robert M. Bernard et al., "A meta-analysis of blended learning and technology use in higher education: from the general to the applied," Journal of Computing in Higher Education, vol. 26, no. 1, pp. 87 - 122, 2014. Available as of April 12, 2017 from https://link.springer.com/article/10.1007\%2Fs12528-0139077-3. 